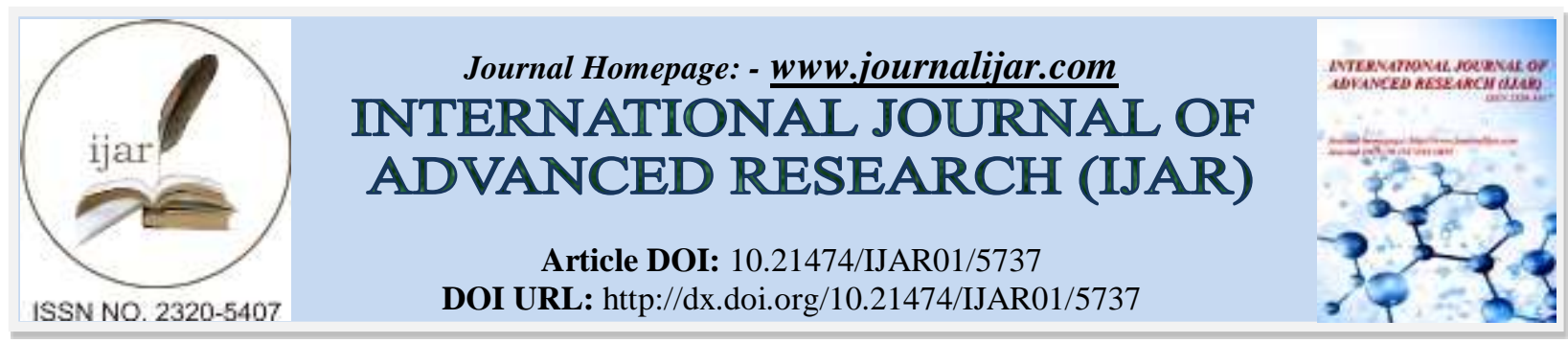

RESEARCH ARTICLE

\title{
PSAMMOMATOID JUVENILE OSSIFYING FIBROMA OF MAXILLA WITH SECONDARY ANEURYSMAL BONE CYST: A CASE REPORT WITH REVIEW OF LITERATURE.
}

\author{
Noha Shaban Abo El Yazeed ${ }^{1}$ and Usama Abd El Raouf El Dakrory ${ }^{2}$. \\ 1. Assistant lecturer in Oral pathology department Ahram Canadian University, MD. Cairo University, \\ 2. Lecturer in Oral and maxillofacial surgery department Misr University for Science and Technology, PhD Cairo \\ University.
}

\section{Manuscript Info}

Manuscript History

Received: 01 September 2017

Final Accepted: 03 October 2017

Published: November 2017

\begin{abstract}
Psammomatoid juvenile ossifying fibroma is a rare, benign boneforming neoplasm with tendency to aggressive local growth that is distinguished from other fibro-osseous lesions primarily by its early age of onset, clinical presentation, aggressive behavior and recurrence tendency. The pathognomonic histopathologic feature is the presence of spherical ossicles, which are similar to psammoma bodies. Very few cases occur in association with the secondary aneurysmal bone cyst $(\mathrm{ABC})$ formation have been reported in the literature, we present here an intraoral case in maxilla with secondary $\mathrm{ABC}$ in a four years old girl.
\end{abstract}

Copy Right, IJAR, 2017,. All rights reserved.

\section{Introduction:-}

Maxillofacial fibro-osseous lesions are a group of jaw disorders characterized by replacement of bone by a connective tissue matrix, which displays varying degrees of mineralization in the form of calcifications, woven bone or cementum-like structures indistinguishable from "cementicles" (8). This group includes a broad group of several entities such as ossifying fibroma, juvenile ossifying fibroma, fibrous dysplasia, cement- ossifying fibroma and familial gigantiform cementoma. (22) In general, fibro-osseous lesions of the maxillofacial region present a diagnostic dilemma for the clinician and pathologist owing to their overlapping clinical and histopathological features.

Psammomatoid juvenile ossifying fibroma (PJOF) is an aggressive variant of ossifying fibroma predominating in the pediatric age group with its peak incidence in the first and second decades of life with almost no sex predilection (4). PJOF is a rare entity. In an extensive review by El Mofty in 2002, he stated that 230 cases were reported till then (24). The term psammomatoid ossifying fibroma was originally used by Gogl in 1949 to describe two cases, one affecting the frontal sinus in a 5-year-old boy and the other was in the ethmoid sinus in a 9-year-old girl (21-24). This was done after Benjamins in 1938 who reported a lesion of the frontal sinus, which he termed "osteoid fibroma with atypical calcification" that was histologically similar to Gogl's cases. Also earlier references by Moser in 1899, Fetissof in 1929, and Ringertz in 1938, had described similar pathological characteristics, but assigned different nomenclature (2). Moser termed the lesion a sarcoma while Fetissof called it "spongy osteoma," and Ringertz called it "juvenile basal fibroma". Makeke in 1983 reviewed 86 cases and considered the lesion to be a variant of osteoblastoma and termed it psammous desmo-osteoblastoma and he refered to the trabecular variant as trabecular desmo- osteoblastoma $(1,24)$. Johnson et al in 1952 was the first to use the term juvenile active ossifying fibroma (3).

Address:- Oral pathology department Ahram Canadian University, PhD candidate Cairo University. 


\section{Histiogenesis:-}

It has been proposed that the mesenchymal cells of the periodontal membrane serve as multipotential precursor cells capable of differentiation into cementum, osteoid or fibrous tissue and give rise to a spectrum of fibro-osseous lesions $(6,10)$. On the other hand, according to some investigators, PJOF perhaps originate from improper development of the tissue generating the bony septa between the roots of molar teeth (4). Moreover, Johnson et al hypothesized that the lesion arise from the overproduction of myxofibrous cellular stroma normally involved in the development of septa in the paranasal sinuses as they enlarge and pneumatize (16).

Several studies demonstrated the presence of nonrandom chromosome break points at Xq26 and 2q33 resulting in (X; 2) translocation (3, 4).Recently, Pimenta et al 2006 described haploinsufficiency of new tumor suppressor gene CDC73 (HRPT2) in several cases of PJOF(17).

\section{Clinically:-}

Johnson et al reviewed 3000 fibro-osseous lesions and found that 112 met the criteria for the juvenile active ossifying fibroma (6). Among the facial tumors, $90 \%$ arise from the paranasal sinuses and the remaining $10 \%$ involve the mandible (4). Few cases involving the temporal bone have also been reported. Faizan et al reported that the maxillary tumors often fill and obliterate the maxillary sinus whereas mandibular tumors usually involve the ramus and angle (5). Very rarely has it been reported extracranially (3\%).

Maxillary PJOF presents clinically with proptosis, visual disturbances, blindness from compression of the optic nerves and orbit, disturbances in ocular mobility, recurrent headaches, and nasal obstruction.(7) Aggressive growth occurs in some but not all cases encroaching adjacent orbital, nasal, and cranial compartments, distorting the face, displacing orbital contents, and blocking normal sinus drainage to form mucoceles. Intracranial extension develops slowly with few neurological signs or symptoms, even though the lesions may be large enough to fill the anterior cranial fossa (12). The dura maintains an effective barrier to invasion of brain. Occasionally, patients will present with meningitis caused by communication between paranasal sinuses and subarachnoid space.(12) Such behavior may be related to younger patient age and the concurrent development of aneurysmal bone cysts, which is seen in some cases(4).

The radiographic appearance manifests as well-demarcated, unilocular or less commonly multilocular radiolucencies with a variable amount of radiopacity, usually manifesting as fine flakes or as ground- glass opacification (5-14). Aggressive forms tend to show more expansile growth pattern than the typical variety. However, they still tend to exhibit sharp demarcation from the normal adjacent bone and this occasionally reflected by an abrupt loss of the overlying cortex (26). The computed tomography has added value to the diagnosis and is used to confirm the extent of the destruction (18).

On gross inspection, PJOF appears as a yellow-white, homogeneous, and firm lobulated mass with gritty consistency. Cystic spaces, although rare, can be present. Histologically the most characteristic feature is the presence of numerous small, round ossicles or "psammomatoid" bodies that are embedded in a cellular fibrous stroma. $(14,16,20)$, the word "psammos" is derived from the Greek word meaning "sand" $(25)$. The ossicles are mineralized collagenous foci that vary from small, smoothly contoured round-to-oval patterns to larger, irregular ones $(13,14,16,19)$. A prominent marginal osteoid rim surrounds the ossicles (4).The ossicles are identified within the bony trabeculae as well as within the adjacent cellular stroma. Their number varies from only a few to a dense population of innumerable spherical bodies. Each one of these bodies shows basophilic center with esinophilc periphery with brush borders.

An aneurysmal bone cyst $(\mathrm{ABC})$ can occur as a secondary change in association with a number of benign and malignant bone lesions, the exact number of PJOF cases converting into $\mathrm{ABC}$ have not been documented in the literature so far, but Makek in his study found out that of the 69 cases of PJOF, only three cases showed ABC transformation. Based on this study the estimated percentage would be $4.3 \%$ (9). Here we report an additional case of PJOF that occurred in the maxilla, and was associated with $\mathrm{ABC}$, which is a rare entity.

\section{Case presentation:-}

Four years old girl was examined in the outpatient clinic of oral and maxillofacial department at The Memorial Souad Kafafi MUST University Hospital complaining from unilateral left maxillary swelling that caused maxillary expansion, lateral globe displacement and proptosis fig (1), she also complained from nasal obstruction. Swelling 
started from three months and grown rapidly. Past medical and family history was noncontributory. Radiographically the CT showed destructive lesion involving maxilla, maxillary sinus up to the base of the orbit fig (2).

Surgical excision of the tumor was decided under general anesthesia. Through Weber-Ferguson incision the lesion was approached extraorally, hemimaxillectomy was performed that extended to palatal midline and posteriorly to posterior palatal margin fig (3). Complete blunt and surgical dissection was performed till complete excision of the tumor as one piece. Surgical closure was performed with suitable techniques.

Simple acrylic obturator was manufactured to obturate the maxillary defect. A future reconstruction plan is prepared using temporalis muscle flap at the age of growth cessation with titanium mesh.
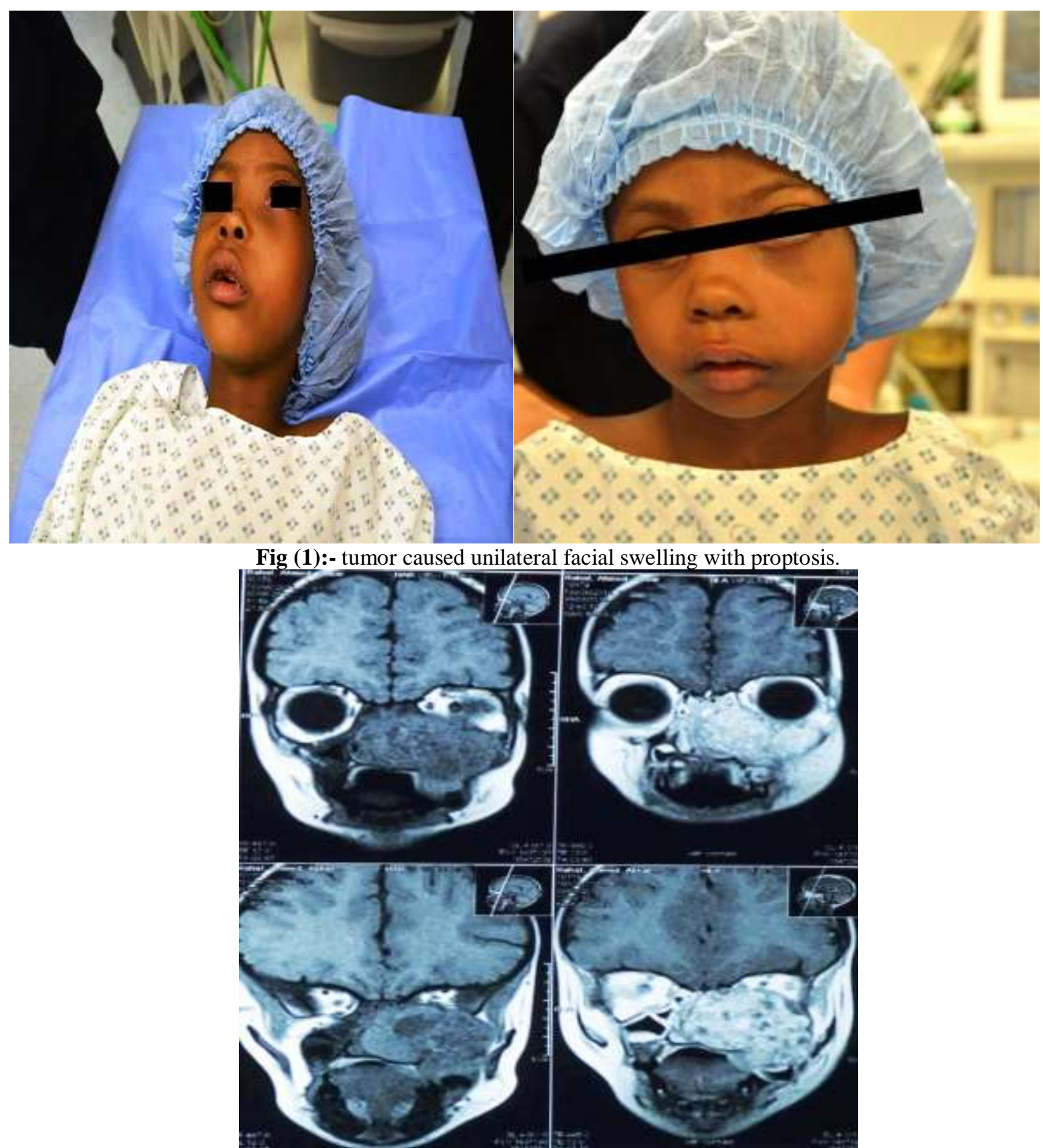

Fig (2):- CT showed destructive lesion involving maxilla, maxillary sinus up to the base of the orbit. 

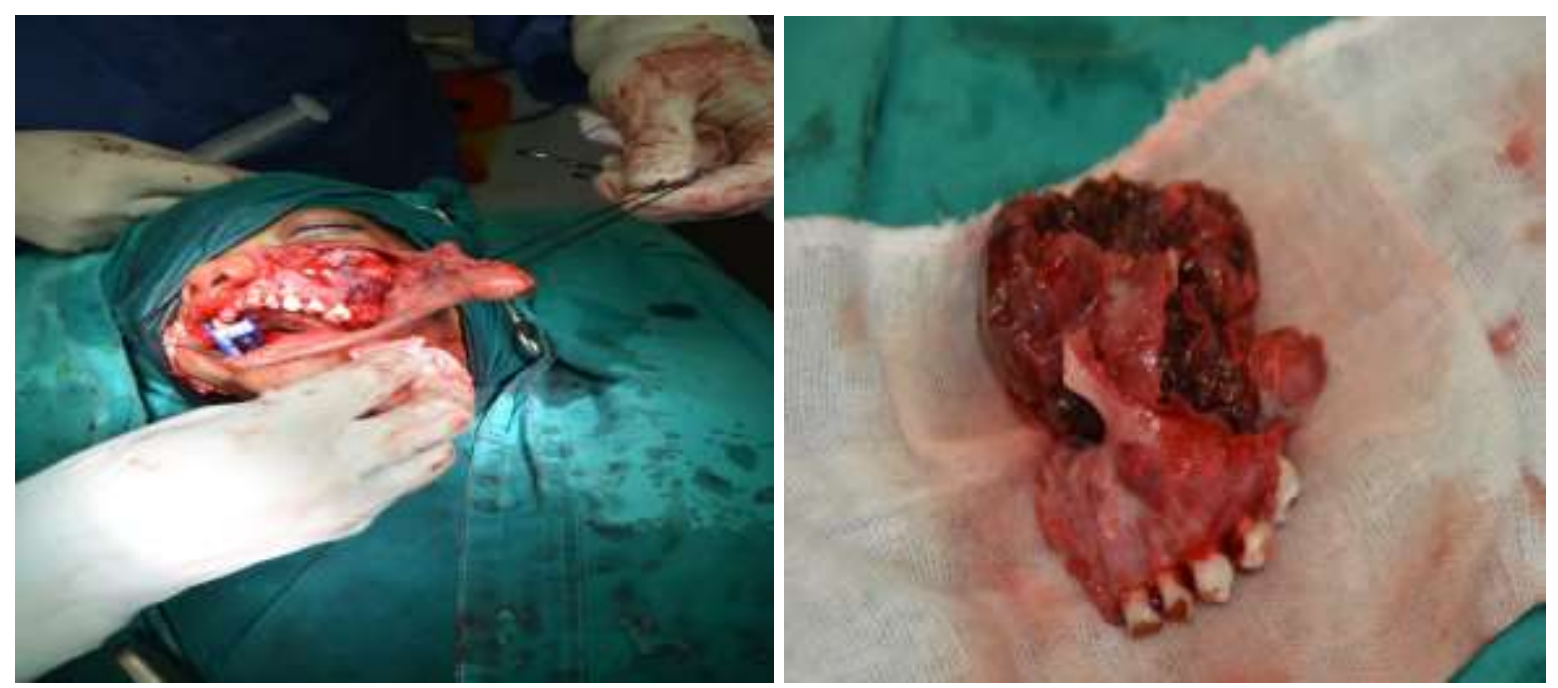

Fig (3):- Hemimaxillectomy through Weber-Ferguson incision.

\section{Histopathology:-}

Tumor tissue formed of immature bony trabeculae rimmed by osteoblasts in some areas embedded in cellular fibrous stroma fig (4), and multinucleated osteoclast-like giant cells was seen with occasional normal mitotic figures. Some psammomatoid bodies as basophilic bodies with esinophilic border were also detected fig (5). Large cavities filled with blood with no endothelial lining rimmed by osteoclasts fig (6). With correlation with young age and aggressive course the diagnosis was PJOF associated with ABC.

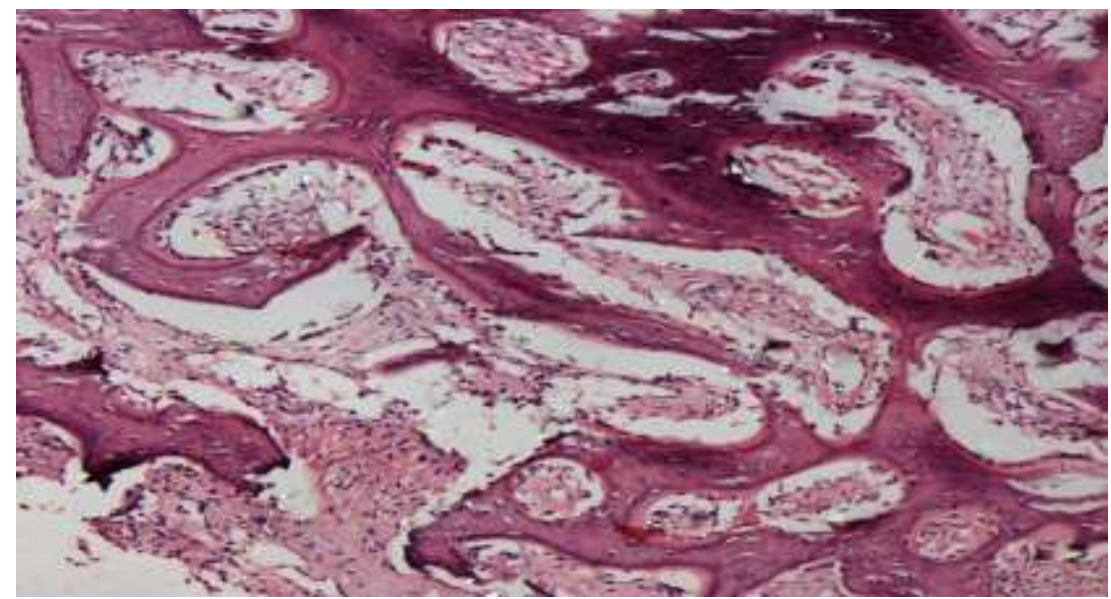

Fig (4):- bony trabeculae with variavle osteoblastic rimming in fibrous stroma. 


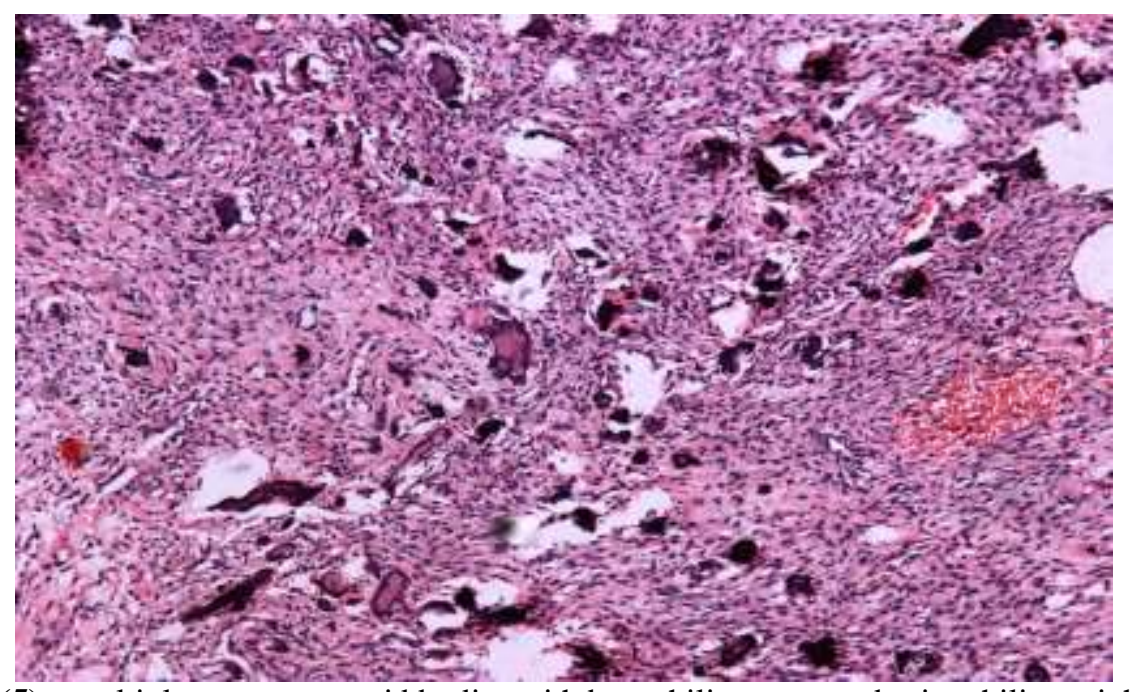

Fig (5):- multiple psammomatoid bodies with basophilic center and esinophilic periphery

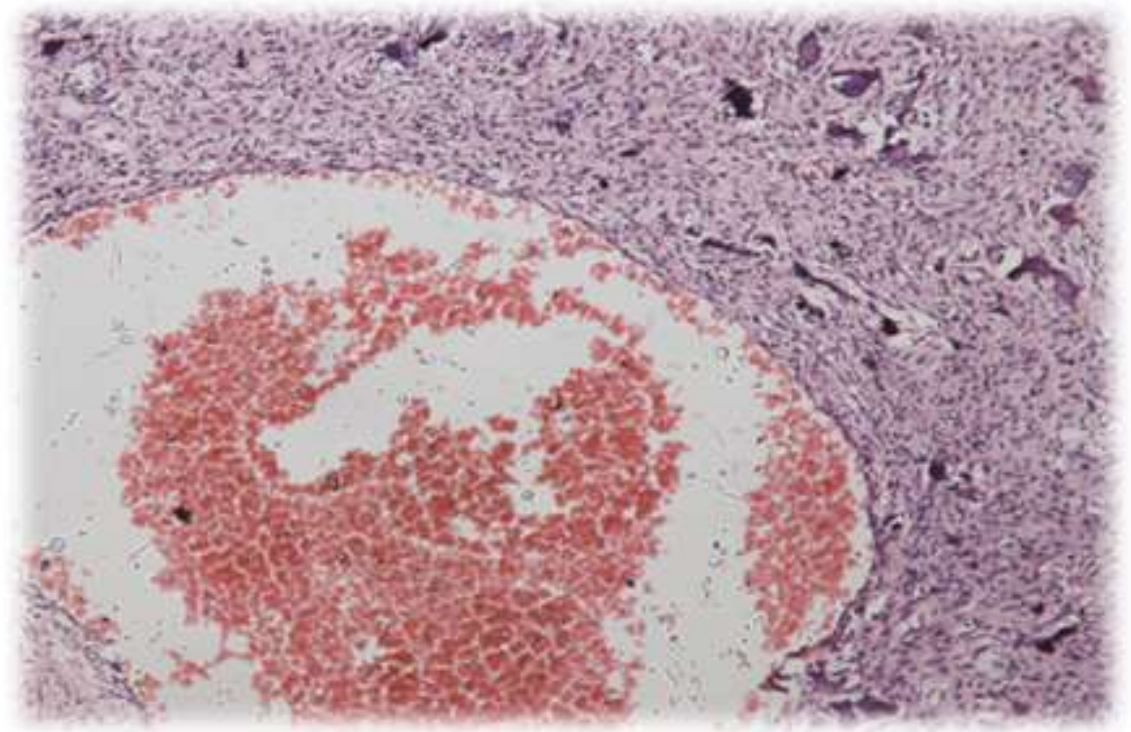

Fig (6):- large cavities filled with blood lacking endothelial lining representing ABC.

\section{Discussion:-}

PJOF has been considered as a distinct disease entity from conventional ossifying fibroma and the other fibroosseous lesions because of its tendency to occur at a young age and its locally aggressive behavior. Moreover, PJOF may clinically manifest with rapid painless expansion of the affected bone as an aggressive lesion mimicking malignancy such as osteosarcoma or chondrsarcoma. So, it is critical to accurately recognize PJOF for making the proper diagnosis and management of this lesion without over emphasizing the situation (14).

The differential diagnosis in conjunction with radiographic findings in this patient initially included aneurysmal bone cyst, central giant cell granuloma, osteogenic sarcoma, and progressive monostotic fibrous dysplasia and nonodontogenic primary tumors of bone, such as osteoblastoma. In addition, locally aggressive odontogenic lesions, such as ameloblastic fibro-odontoma, as well as cystic lesions as calcifying odontogenic cyst and keratocystic odontogenic tumor. Morover vascular tumors can also have rapid growth and may be considered in the differential diagnosis. For example, central hemangioma grows rapidly and commonly presents as a radiolucent mass in children and young adults. Arteriovenous malformations also exhibit rapid growth, but usually display bruits on examination (14). 
It is important to distinguish PJOF from central cementifying fibroma which is a benign jaw lesion of odontogenic origin arising in the molar and premolar regions of the maxilla with average age range in the third or fourth decade of life with a distinctly female predilection $(3.4,7)$. Radiographically, central cementifying fibroma is a wellmarginated, unilocular, radiolucent or variably opacified lesion. Microscopically, central cementifying fibromas consist of fibrous stroma with dense cellularity and small, spherical calcifications "cementicles". Unlike PJOF, central cementifying fibromas has very low recurrence rate (7).

Histologically, psammoma-like bodies in PJOF were found to possess a dark rim of crystals from which small spicules and needle-like crystalloids project toward the periphery (21). The stroma varies from being loose and fibroblastic to intensely cellular with minimum intervening collagen. PJOF contains deeply basophilic concentrically lamellated particles as well as irregular thread-like or thorn-like calcified strands in a hyalinized stroma. In contrast to fibrous dysplasia, osteoclasts and osteoblasts typically line the trabeculae, which are composed of entrapped lamellar bone. Other features such as trabeculae of woven bone as well as lamellar bone, pseudocystic stromal degeneration, and hemorrhages result in areas similar to an aneurysmal bone cyst (2).

Treatment of PJOF has been controversial. Complete removal by enucleation alone or with curettage as well as en block resections are common therapeutic options. Most cases require tissue removal as much as possible while protecting adjacent vital structures to prevent recurrences. Our case required hemimaxillectomy to ensure total excision of the mass. The reported recurrence rate ranges between 30 and $58 \%(4,23)$. Radiotherapy has been proven ineffective and contraindicated due to an increased incidence of malignant transformation ranging from 0.4 to $40 \%$. Despite the aggressive behavior, no metastasis has been reported (11). Therefore, conservative treatment of the jaw lesions by enucleation and curettage has been reported to be successful in non-aggressive cases.

\section{References:-}

1. Alawi F. Benign fibro-osseous diseases of the maxillofacial bones - A review and differential diagnosis. Am J Clin Pathol. 2002; 118(Suppl):S50-70.

2. Barnes L, Eveson WJ, Reichart P, Sidransky D. WHO Classification of Tumours - Pathology and Genetics Head and Neck tumours. France: IARC press; 2005.

3. Bruce MW, Tuyethoa NV, James GS, Craig BF, Glen DH, Dennis KH.

4. Aggressive psammomatoid ossifying fibromas of the sinonasal region a clinicopathologic study of a distinct group of fibro-osseous lesions. Cancer 1995; 76(7):1155-65.

5. El-Mofty S. Psammomatoid and trabecular juvenile ossifying fibroma of the craniofacial skeleton: Two distinct clinicopathologic entities. Oral Surg Oral Med Oral Pathol Oral Radiol Endod. 2002; 93:296-304.85.

6. Faizan A. Benign fibro-osseous diseases of the maxillofacial bones. Am J Clin Pathol 2002; 118:50-70.

7. Johnson LC, Yousefi M, Vinh TN, Heffner DK, Hyams VJ, Hartman KS. Juvenile active ossifying fibroma. Its nature, dynamics and origin. Acta Otolaryngol Suppl. 1991; 488:1-40.

8. Liliya A, Mark F, Tabor H. Pathologic quiz case: A sino-orbital mass in a 13 years old adolescent girl. Arc of pathol and lab med 2003; 127(7):301-02.

9. MacDonald DS, Jankowski. Fibro-osseous lesions of the face and jaws. Clinical Radiol 2004; 59:11-25.

10. Makek M. Clinical pathology of fibro-osteo-cemental lesions of craniofacial skeleton and jaw bones. Basel (Switzerland) Karger. 1983:128-227.

11. Manjunatha BS, Das N, Naik S, Gowramma R. Trabecular variant of juvenile aggressive ossifying fibroma of anterior mandible. Pediatr Rep. 2012; 4:e24.

12. Martin Hasselblatt, et al. Juvenile psammomatoid ossifying fibroma of the neurocranium. Report of four cases. J Neurosurg 2005; 102: 1151-54.

13. Michael TL, Heiserman JE, Coons SW, Ragsdale BD, Spetzler RF. Juvenile active ossifying fibroma. J Neurosurg 1997; 86:279-85.

14. Nair, Preeti, Anil Kumar, Karthik Hegde, and Shiba Neelakantan. "Psammomatoid juvenile ossifying fibroma: A case report with literature review." Journal of Indian academy of oral medicine and radiology 22, no. 5 (2010): 53.

15. Neville, Damm, Allen, Bouquot. Oral and maxillofacial pathology (3rd ed). 564-66.

16. Ono A, Tsukamoto G, Nagatsuka H, Yoshihama Y, Rivera RS, Katsurano M, et al. An immunohistochemical evaluation of BMP-2, -4, osteopontin, osteocalcin and PCNA between ossifying fibromas of the jaws and peripheral cemento-ossifying fibromas on the gingiva. Oral Oncol. 2007; 43:339-44.

17. Park S, Jae B, L Lee JH, Cho KJ. Juvenile Ossifying Fibroma: A Clinicopathologic study of 8 cases and comparison with craniofacial fibro-osseous lesions. The Kor J of Pathol 2007; 41:373-79. 
18. Pimenta FJ, Gontijo Silveira LF, Tavares GC, Silva AC, Perdigão PF, Castro WH, et al. HRPT2 gene alterations in ossifying fibroma of the jaws. Oral Oncol. 2006;42:735-9

19. Rao, Sudhapalli Chidanand, Ramakant Dandriyal, Gaurav Sapra, Himanshu Sharma, Umang Agarwal, and Nikhil Pandit. "Psammomatoid juvenile aggressive ossifying fibroma of mandible." National journal of maxillofacial surgery 3, no. 1 (2012): 47.

20. Ross RD. Benign fibroosseous lesions and bone tumours of the jaws. Oral and maxillofacial pathology. http://www.thedentalforum.org/ Lecture Handouts \& References/Foss2005/BFOL\%20Lecture-Foss.pdf

21. Singh I, Ghimire A, Bhadani P, Nepal A, Maharjan M, Gauum D, et al. Proptosis in a young child. Indian journal of pediatrics 2006; 73:537-38.

22. Solomon MC, Khandelwal SAR, Carnelio S. Psammomatoid juvenile ossifying fibroma of the mandible - A histochemical insight! Internet J Dent Sci. 2009;7.

23. Su L, Weathers DR, Waldron CA. Distinguishing features of focal Cemento-osseous dysplasia and cementoossifying fibromas: I. A Pathologic spectrum of 316 cases. Oral surg Oral Med Oral Pathol Oral Radiol Endod. 1997;84(3):301-9. doi: 10.1016/S1079-2104(97)90348-6.

24. Sun G, Chen X, Tang E, Li Z, Li J. Juvenile ossifying fibroma of the maxilla. Int J Oral Maxillofac Surg 2007;36:82.

25. Thankappan S, Nair S, Thomas V, Sharafudeen KP. Psammomatoid and trabecular variants of juvenile ossifying fibroma - two case reports. Indian J Radiol Imaging. 2009; 19:116-9.

26. Vandekerckhove K,Van-den AK,Van-den BC, Verstraete K, Meire F. Psammomatoid ossifying fibroma of the ethmoid. Bull Soc belge Ophtalmol 2003; 287:9-14.

27. Yonetsu K, Nakamura T. CT of calcifying jaw bone diseases. Am J Res 2001; 177:937-43. 